\title{
Curcumin modified Titanium Dioxide Nanotubes with Enhanced Visible Light Photocatalytic Performance
}

\author{
Montri Aiempanakit ${ }^{1}$, Thanatchaporn Tabtimsri ${ }^{2}$, Narit Triamnak $^{3}$, Cheewita Suwanchawalit ${ }^{2}$ \\ ${ }^{1}$ Department of Physics, Faculty of Science, Silpakorn University, Sanam Chandra Palace Campus, \\ Nakhon Pathom, Thailand 73000 \\ ${ }^{2}$ Department of Chemistry, Faculty of Science, Silpakorn University, Sanam Chandra Palace Campus, \\ Nakhon Pathom, Thailand 73000 \\ ${ }^{3}$ Department of Materials Science and Engineering, Faculty of Engineering and Industrial Technology, \\ Silpakorn University, Sanam Chandra Palace Campus, Nakhon Pathom, Thailand 73000 \\ *E-mail: suwanchawalit_c@su.ac.th
}

doi: $10.20964 / 2019.02 .28$

Received: 10 October 2018 / Accepted: 20 November 2018 / Published: 5 January 2019

In this study, curcumin modified $\mathrm{TiO}_{2}$ nanotubes (Cur-TNT) were prepared by a modified impregnationelectrochemical anodization method with $0.01,0.025,0.05 \mathrm{mM}$ of curcumin concentrations. The physical properties of the Cur-TNT were studied by several techniques such as X-ray powder diffraction (XRD), scanning electron microscopy (SEM), energy dispersive X-ray spectroscopy (EDS), Fouriertransformed infrared spectroscopy (FT-IR), and UV-Vis diffused reflectance spectroscopy (DRS). The XRD patterns data revealed anatase phase for both the TNT sample and the Cur-TNT samples. The high magnification images from SEM technique showed that the TNT sample and the Cur-TNT samples possess nanotube-like structures with an average diameter of $85 \mathrm{~nm}$. The FT-IR spectra exhibited the characteristic bands of the $\mathrm{TiO}_{2}$ and hydroxyl groups on the TNT surface. Instead of hydroxyl groups, the characteristic bands of curcumin were observed on the surface of the Cur-TNT samples. The EDS results complementarily confirmed the existence of $\mathrm{Ti}, \mathrm{O}, \mathrm{C}$ as the main elements of the Cur-TNT samples. Interestingly, the DRS spectra of the Cur-TNT samples extended into the visible region. The photocatalytic properties of the Cur-TNT samples were evaluated from the degradation of methylene blue under visible light irradiation. It was found that the Cur--TNT samples exhibited higher photocatalytic performance than the TNT sample. A possible photocatalytic mechanism has also been proposed.

Keywords: $\mathrm{TiO}_{2}$ nanotubes, Curcumin modified $\mathrm{TiO}_{2}$, Electrochemical anodization method, Visible photocatalyst, Degradation of methylene blue

FULL TEXT 
(C) 2019 The Authors. Published by ESG (www.electrochemsci.org). This article is an open access article distributed under the terms and conditions of the Creative Commons Attribution license (http://creativecommons.org/licenses/by/4.0/). 